\title{
浅谈旁扫声呐技术在软体排搭接宽度检测中的应用
}

\author{
刘锦程 ${ }^{1}$ 党晓斌
}

1 正元地理信息集团股份有限公司山东分公司 2 沈阳城市建设学院

DOI:10.32629/gmsm.v3i1.516

[摘 要] 随着国家经济社会的发展,航道工程、水运工程在国民经济建设中发挥了重要的作用,软体排在相关工程的护坡、护堤中得到了广泛的应用。 旁扫声呐具有声图成像分辨率高、数据采集效率高、成本低等优点,在软体排搭接宽度检测中得到了有效的应用。本文结合具体工程,简要介绍了软体 排制作、铺设及外业检测、成果分析的过程,通过对成果数据的判断、计算,证实旁扫声呐技术可以应用于软体排搭接宽度的检测,达到了预期的效果! [关键词] 旁扫声呐技术; 软体排搭接; 检测

\section{1 软体排制作与铺设流程}

1. 1 软体排的作用

水下铺排的主要作用是保护铺设范围内的河床底质不被水冲蚀, 从而 达到护底、护脚、防止淘刷、保护工程基础, 进而保护上部实体结构的稳 定性的目的。

\section{2 软体排的制作与规格}

护底结构主要采用软体排, 堤身排体布采用 $350 \mathrm{~g} / \mathrm{m}^{2}$ 机织布, 余排以及 高滩段堤身排排体布采用复合土工布, 由 $350 \mathrm{~g} / \mathrm{m}^{2}$ 机织布和 $150 \mathrm{~g} / \mathrm{m}^{2}$ 无纺布 针刺复合而成。

堤身下排体施工期压载采用长管状砂肋, 直径 0.3 米, 间距 1.0 米。排体 间搭接宽度不小于 $2 \mathrm{~m}$ 。

余排压载采用硂联锁块, 联锁块为矩形硂小方块, 各堤段余排方块规 格一般为 $480 \mathrm{~mm} \times 480 \mathrm{~mm} \times 120 \mathrm{~mm}$ 和 $480 \mathrm{~mm} \times 480 \mathrm{~mm} \times 160 \mathrm{~mm}$ 。水深较浅的高滩 地, 采取防老化措施, 排布采用加防老化剂的丙纶长丝机织布和涤纶无纺 布的复合布, 且铺设时要求无纺布在上, 硅联锁块采用防老化丙纶绳联接, 方块规格为 $480 \mathrm{~mm} \times 480 \mathrm{~mm} \times 120 \mathrm{~mm}$, 联锁块上方抛 $60 \mathrm{~cm}$ 厚块石防止绳和布 体老化。砤联锁块体边缘 5 范围内均采用 $480 \mathrm{~mm} \times 480 \mathrm{~mm} \times 20 \mathrm{~mm}$ 规格。

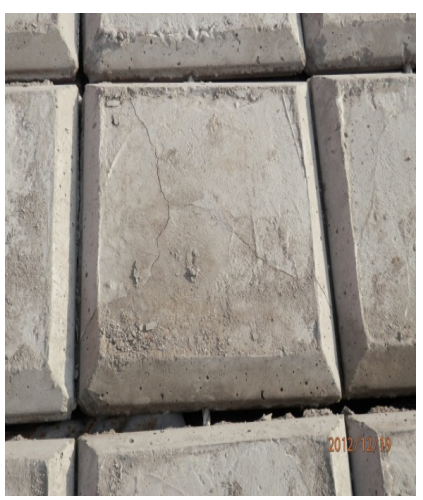

混凝土块 $(48 \mathrm{~cm} \times 48 \mathrm{~cm})$

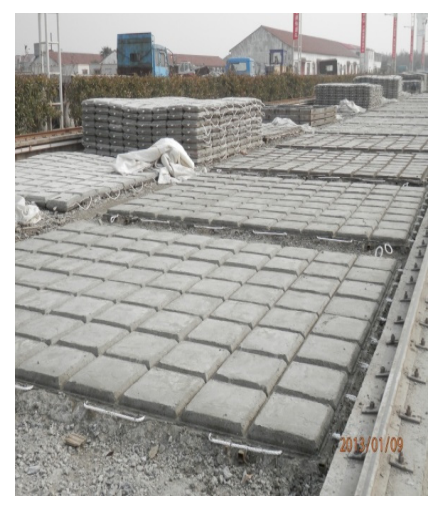

硂联锁块 $(3.98 \mathrm{~m} \times 4.98 \mathrm{~m})$
本文讨论的工程应用软体排主要包括沙肋软体排和硂联锁块软体排。 砂肋软体排主要由土工布 $\left(230 \mathrm{~g} / \mathrm{m}^{2}\right)$ 、加筋带、长管袋砂肋制作而成; 硂 联锁块软体排主要由复合土工布 $\left(500 \mathrm{~g} / \mathrm{m}^{2}\right)$ 、加筋带、砤联锁块制作而成。

砤联锁块采用C 20 硂, 尺寸分三种: $480 \mathrm{~mm} \times 480 \mathrm{~mm} \times 120 \mathrm{~mm} /$ 块、 $480 \mathrm{~mm}$ $\times 480 \mathrm{~mm} \times 160 \mathrm{~mm} /$ 块、 $480 \mathrm{~mm} \times 480 \mathrm{~mm} \times 200 \mathrm{~mm} /$ 块, 每平方米 4 块, 硂联锁块边 缘设置倒角, 以适应变形; 排边 5 范围为加厚硁联锁块, 尺寸为 $480 \mathrm{~mm} \times$ $480 \mathrm{~mm} \times 200 \mathrm{~mm}$ 。每个砤联锁块大小为 $3.98 \mathrm{~m} \times 4.98 \mathrm{~m}$, 横向为 3.98 米, 由 8 块 混凝土块组成, 每相邻两个混凝土块之间的间距为 $2 \mathrm{~cm}$; 纵向为 4.98 米, 由 10 块混凝土块组成, 相邻两个混凝土块之间的间距也为 $2 \mathrm{~cm}$ 。

\section{3软体排铺设}

软体排由专业加工厂制作, 混凝土联锁块在施工临建基地内的预制厂 成片预制, 船运到铺排现场。

本工程滩面高程基本在 $-1.0 \mathrm{~m}$ 以下, 软体排可采用 $2000 \mathrm{~T}$ 以上专用铺排 船乘潮进行铺设, 其吃水深度为 $-2.0 \mathrm{~m}$ 米左右。滩面高程在 $-1.0 \mathrm{~m} \sim-3.0 \mathrm{~m}$ 左右滩地可乘高平潮位铺设, 较深部位可全天候铺设, 南、北潜堤局部滩面 较高, 需选择吃水较浅铺排船候潮作业。排体铺设主要施工工艺如下:

\subsection{1定位}

在沉排过程中采用RTK实时跟踪指挥其定位, 确保排体按设计要求的 位置入水, 并保证符合排体搭接要求。沉排船由钢缆控制其定位和位移, 沉排时要求船舶能平行位移。

\subsection{2排体沉放}

(1) 专用铺设船介绍。(1)沉排滑板。滑板是一种大型平面钢结构, 设置 在船舷一侧, 外缘以钢丝绳一滑轮组悬吊于甲板边的将军柱上, 可在一定角 度内变幅。该滑板不但可提供对悬垂排体的支撑, 引导软体排水下定位, 而 且对排首水下就位和为在船甲板上进行排体压载物与排布的固定作业提供 了十分有利的作业面积和工作条件。(2)卷筒与导梁。铺排船上配置有土工 布贮存卷筒, 卷筒设置在船舶的中段, 靠近右舷的甲板上。施工中土工布从 卷筒中拉出, 在甲板和滑板上展平, 然后充砂形成砂肋软体排。该卷筒采用 双向变速驱动装置和可调节制动力矩的制动器, 既作为排体土工布的咜存 装置, 又在排体铺设过程中起到控制铺排速率和制动的作用, 使排体铺设速 度得到有效控制。用以控制软体排沉放速度, 使排体受力得到改善, 确保铺 排质量。导梁与卷筒平行布置, 为箱型结构。土工布由卷筒拉出后经导梁引 向甲板。导梁的主要作用是改善卷筒的受力状态, 当软体排拉力增大时, 其 与导梁的摩阻力亦随之增大, 可保证排体均匀沉放及卷筒受力的稳定性。(2) 铺设前的准备工作。土工布和砤联锁块均在陆上预制, 土工布采用厂家生产 的单幅土工布在陆上加工厂拼成整幅 (宽30 40m, 长度根据不同堤段设计 护底宽度确定, 一般在250 300米之间)。排体运到现场后, 铺排船将滑板放 成水平, 由铺排船上的起重机将排体吊到甲板上。(3) 土工布上卷筒。将一 块成捆的土工布排体吊到铺排船卷筒前的甲板上拆封展开, 验证排体的尺 寸与设计是否相符, 符合要求后才能开始卷排。卷筒上每米设有吊鼻一个, 吊鼻设钢丝绳, $\Phi 12$ 每根钢丝绳长度为 $20 \mathrm{~m}$, 钢丝绳另一端吊扣通过 $\Phi 15$ 卡 环与双股 $\Phi 20$ 丙纶绳 $($ 长 $30 \mathrm{~m} \times 2$ 双抽) 连接, 丙纶绳另一端与排尾预缝的直 径 $50 \mathrm{~mm}$ 的加筋环连接, 缝制时加筋环已进行加固, 启动卷筒开始卷排。卷排 时铺排操作人员将布两边拉紧, 保证排布卷紧卷匀, 卷排时将排头展开平铺 在铺排船的甲板上。(4) 软体排沉放。当滑板下倾至软体排缓缓下滑时, 锁 定滑板倾角, 并利用铺排船上卷筒的刹车装置控制排体下滑长度, 可使铺排 船后移的距离与土工布软体排的下滑长度基本相同步。利用沉至海底的部 
分排体的自重起针锭作用, 根据不同的水深可确定排首针固长度, 超过针 固长度后, 即可通过移船来使排体受拉而平整地铺设至海底。利用滑板倾 斜进行导铺, 随着船体沿铺设方向的平移, 使排体反向同步入水。

为了使软体排在受控状态下铺设下滑, 并防止其扭曲, 采用可俯仰变 幅的沉排滑板将排体由船上引人水中。合理调整滑板倾角和每一移船步距 内甲板外缘成型砂肋的条数, 始终保证滑板上的排重产生的下滑力能克服 排体与甲板间的静摩擦力, 使排体成型与移船铺设实现连续流水作业。

\section{2 软体排搭接宽度检测内容及原理}

2.1 对软体排搭接检测的主要内容

主要内容包括: (1) 软体排水下铺设时, 检测水下是否出现堆积、翻排; (2) 两张软体排的结合部分是否达到要求的程度 (重复3-5米), 是否出现脱 接现象, 本工程主要使用侧扫声呐技术对软体排搭接进行扫测 (抽检), 以 判断所抽检软体排搭接是否符合设计要求。

2.2 侧扫声纳测量原理

本次软件排搭接宽度的检测, 是通过测量船拖电电缆将侧扫声纳拖鱼, 拖电在离船舷一定距离和一定深度上进行测量。换能器按一定的频率发射 声波并接收, 则得到一系列回波。由于换能器基阵收到水底各点回波的时 间有先后之分, 故通过模数转换电路以声图形式显示、记录。当声波传播 距离越远时, 换能器接收到的回波的时间就越长。如果水底铺设的软体排 凸凹不平或排体未搭接, 使得水底或软体排有的地方被声波照射, 有的地 方没有被声波照射, 而没有被声波照射到的地方就会产生阴影, 也就反映 出水底铺设软体排的搭接状况。

\section{3 外业实施}

3. 1 测线布设

对一个检测面 (搭接面) 进行检测时, 则采用双侧扫测的方式进行布线, 如图2-1所示:

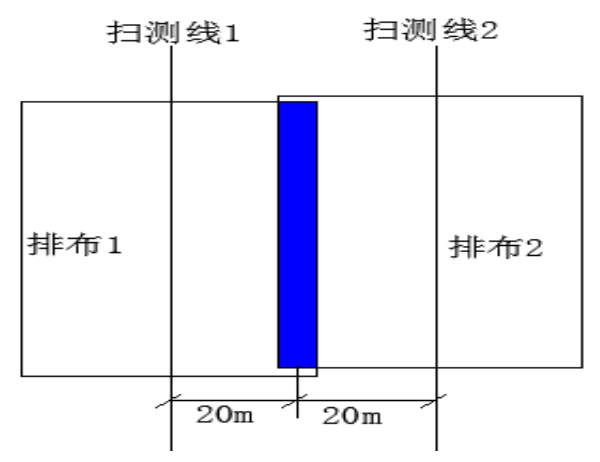

图2 扫测线布设图

图中蓝色部分是需要检测的区域, 为保证检测影像的质量, 测线的长 度将超出检测区 $50 \mathrm{~m}$ 的范围。

3.2 仪器校准

扫测前在已知控制点上对RTK-DGPS接收机进行比对, 其定位中误差应 在 $0.03 \mathrm{~m}$ 以内, 满足定位限差要求。

扫测前对侧扫声纳整个工作系统进行测试校准, 保证整套系统正常工作。

3. 3 扫测实施

RTK-DGPS在控制点比对完成后, 进入扫测实施阶段。

本次测量使用Trimble SPS 882型RTK-DGPS接收某基站差分信号进行 平面定位, 采用美国Coastal海洋图像公司的HYPACK MAX专业水道测量软 件进行导航, SonarPro进行侧扫影像数据采集。

为确保扫测图像清晰, 扫测过程中测船航速低于 4 节, 航行方向严格沿着
测线方向。扫测覆盖范围为测线左右两侧各 $50 \mathrm{~m}$ 或 $70 \mathrm{~m}$, 以满足实际工作需求。

\section{4 资料分析}

外业数据采集完成后, 立即投入内业编辑与处理工作, 通过侧扫声纳 专用软件SonarPro进行数据回放并进行影像分析, 通过专业的分析软件对 侧扫声纳图像进行判读, 进而对水底软体排搭接位置进行坐标定位、量距, 获得准确位置, 并计算出软体排的搭接宽度。

图3为在现场利用Klein3000型侧扫声纳, 拖鱼采用舷挂侧拖式进行搭 接扫测的影像图, 检测已铺设的两张软体排布的搭接情况。如图中青色箭 头所示, 很显然, 软体排排体的水下搭接宽度可通过图像进行判读。

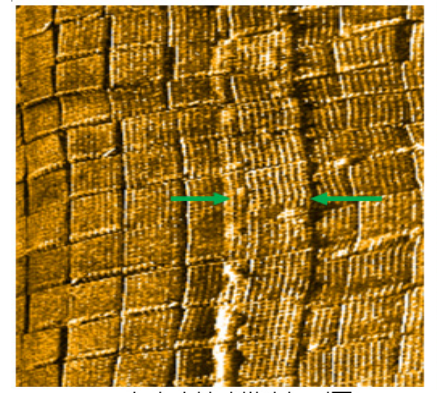

混凝土连锁片搭连扫测图

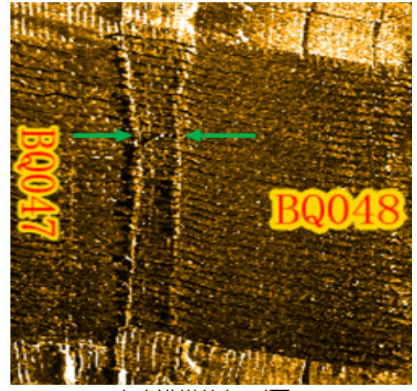

沙肋排搭接扫测图
图3 水下排体的搭接示意图

排体中每个大的方框代表 $5 \mathrm{~m} \times 4 \mathrm{~m}$ 的排体, 而小格区域是 $0.5 \mathrm{~m}$ 边长的混凝 土连锁片。很显然, 利用旁扫测量技术可以很准确地进行搭接的判读。利用 Klein 3000 型侧扫声纳检测的图像至少可以判读 $0.25 \mathrm{~m}$ 精度的排体测量值。

坐标提取时, 先用SonarPro软件从侧扫声纳图像中提取坐标的经纬度, 再通过参数转换, 把经纬度转化成北京54坐标。

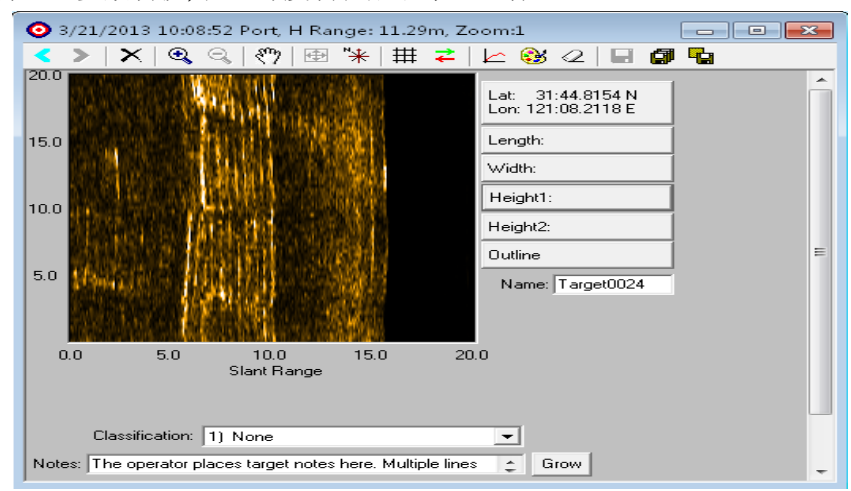

图4 用SonarPro软件提取排体坐标的经纬度

\section{5 结束语}

目前, 软体排在水运工程中得到了广泛的应用, 为了保障水工建筑物 的安全及确保航道的安全运行, 软件排搭接宽度检测也成为工程质量检测 的类型之一。旁扫声呐技术在软件排搭接宽度检测中成为一种主要技术手 段, 随着对海洋测量技术的研究及软硬件设备的发展, 相信该技术在软体 排搭接宽度的研究和应用会越来越广泛。

[参考文献]

[1]程婷. 声呐旁扫技术在检测软体排铺设质量中的应用 [J]. 科技 风,2018(10):184.

[2]金剑. 实时声呐检测技术在水下软体排铺设质量检测中的应用 [J]. 中国水运,2018(01):55-56.

[3]张才俊,郭素明,李少俊.水下软体排铺设质量检测技术对比[J].水 运工程,2016(02):10-14. 